\title{
Pragmática transcendental y filosofía social: Karl-Otto Apel, Jürgen Habermas y la nueva fundamentación de la Teoría Crítica
}

\author{
Transcendental pragmatics and social philosophy: Karl-Otto \\ Apel, Jürgen Habermas and the new foundation of Critical \\ Theory
}

\begin{abstract}
Resumen: el objetivo de este artículo es defender que la pragmática transcendental ofrece la fundamentación normativa de la teoría crítica como teoría de la acción comunicativa ${ }^{1}$. Para ello se expondrá en primer lugar el problema de la normatividad en la Teoría Crítica de la sociedad. Tras describir la forma que adquiere esta teoría tras el giro lingüístico operado por Jürgen Habermas, se reconstruirán en tercer lugar los elementos fundamentales de la pragmática transcendental apeliana y habermasiana. En cuarto y último lugar se mostrará que este modelo constituye la fundamentación normativa de la nueva teoría crítica.

Palabras clave: pragmática transcendental; Teoría Crítica; Habermas; Apel; normatividad
\end{abstract}

\section{CÉSAR ORTEGA-ESQUEMBRE*}

\begin{abstract}
: the aim of this paper is to argue that transcendental pragmatics constitutes the normative foundation of critical theory, understood as theory of communicative action. To that end, the issue of normativity within Critical Theory discussions is first exposed. After describing the form this theory takes from the linguistic turn carried out by Jürgen Habermas, key elements of Karl Otto Apel's and Jürgen Habermas' transcendental pragmatics are thirdly reconstructed. Fourth paragraph shows that this model operates as the normative foundation of the new critical theory.
\end{abstract}

Keywords: transcendental pragmatics; Critical Theory; Habermas; Apel; normativity

\section{Introducción}

Aunque el afán de diálogo interdisciplinar con las diversas áreas científicas y tradiciones filosóficas no es precisamente un rasgo extraño a los autores que, en general, podemos considerar pertenecientes a la Teoría Crítica, lo cierto es que Karl-Otto Apel constituye probablemente el más excepcional de los ejemplos de este afán. Tal cosa es cierta, sobre todo, para el caso de las discusiones con otras tradiciones de filosofía. Si

07/03/2019. Aceptado: 29/07/2019.

* Investigador Postdoctoral en el Departamento de Filosofía de la Facultad de Filosofía y Ciencias de la Educación de la Universidad de Valencia. Correo electrónico: cesar.ortega@uv.es Líneas de investigación: teoría crítica de la sociedad, ética del discurso, filosofía moral, política y social. Publicaciones recientes: "Críticas inmanentes al pensamiento de Jürgen Habermas: la teoría de la lucha por el reconocimiento y la ética de la razón cordial". Recerca, 21(1), 2020; "La recepción del pensamiento de Marx en el joven Habermas". Ideas y valores, 67(167), 2018, 13-36.

2 Este estudio se inserta en el Proyecto de Investigación Científica y Desarrollo Tecnológico FFI2016-76753-C21-P, financiado por el Ministerio de Economía y Competitividad. 
dentro del grupo de autores que conformaron el proyecto originario de la Teoría Crítica frankfurtiana durante los años treinta era Herbert Marcuse quien actuaba como auténtico "ímpetu filosófico" -cosa desgraciadamente olvidada, por cierto, por aquellos que ven en su figura tan sólo al padre de la New Left-, en el marco de lo que hoy llamamos "segunda generación" de la Escuela de Frankfurt ha sido Apel quien ha ejercido el honorable rol de "maestro de filosofía". Acaso no sea casualidad que tanto Marcuse como Apel iniciaran sus recorridos filosóficos desde una experiencia filosófica significativamente idéntica, a saber, la experiencia - pronto abandonada por ambos- de fascinación hacia la que constituye tal vez la más fecunda tradición de filosofía de la primera mitad del siglo XX: la hermenéutica de la facticidad de Martin Heidegger.

Las palabras anteriores parten, sin embargo, de un supuesto que está lejos de ser evidente para la literatura especializada. Me refiero al hecho de considerar a Karl-Otto Apel como un miembro más, junto con otros autores como Jürgen Habermas o Albrecht Wellmer, de la segunda generación de la Escuela de Frankfurt (cf. Kettner, 1996). Al margen de la pregunta por la pertenencia o no de un determinado autor a una determinada "escuela" de pensamiento, cuya respuesta acaso sirva más para alimentar la curiosidad personal que para resolver un asunto científico, este supuesto constituye en el fondo un problema del mayor interés filosófico. Con la afirmación consciente y reflexiva de esta pertenencia uno se compromete con una serie de supuestos teóricos cuya corrección, a su vez, es preciso someter a crítica. Mostrar tal pertenencia es un objeto mediato de este trabajo. En lo que sigue voy a tratar de argumentar que la pragmática transcendental constituye el fundamento normativo de esa nueva teoría crítica de la sociedad que a partir de Habermas se inscribe en el llamado "paradigma lingüístico". Para ello expondré en primer lugar el problema de la normatividad en la Teoría Crítica de la sociedad. Tras describir la forma que adquiere la Teoría Crítica tras el giro lingüístico operado por Habermas, reconstruiré en tercer lugar los elementos fundamentales de la pragmática transcendental. En cuarto y último lugar trataré de probar que este modelo, defendido por Apel en términos de un análisis pragmático-transcendental del entendimiento lingüístico y por Habermas en los de una reconstrucción pragmático-universal de la comunicación, constituye la fundamentación normativa de la nueva teoría crítica de la sociedad.

\section{El papel de la normatividad en la crítica materialista de la sociedad}

El primer intento sistemático de ofrecer una teoría materialista de la sociedad con intención crítica debe ser localizado, si no me equivoco, en la disputa entre el joven Marx y la crítica de la religión de los jóvenes hegelianos. En confrontación sobre todo con Ludwig Feuerbach, durante los primeros años cuarenta del siglo XIX Marx había tratado de sustituir la crítica de la religión, que operaba en los términos de una "alienación" de la esencia humana, por una crítica materialista de la sociedad capaz de explicar las causas sociales de dicha alienación (Marx, 2013; Bauer y Marx, 2009). La exposición del contenido ideológico de la religión, es decir, de su función legitimadora, servía por tanto a Marx tan sólo como paso previo a la crítica de aquella sociedad que originaba las contradicciones encubiertas. Ahora bien, aunque con ello Marx daba el primer paso en la dirección de una teoría crítica de la sociedad, lo cierto es que no fue hasta la elaboración de sus Manuscritos económico-filosóficos, redactados en 1844, 
que esta teoría de la sociedad, todavía muy filosófica, quedó saturada de lo que en adelante constituiría su auténtico núcleo: los estudios de economía política². Alejándose no sólo de los jóvenes hegelianos, sino también del socialismo utópico, Marx tenía que demostrar que la sociedad emancipada no era tan sólo un ideal moral al que aspirara la conciencia socialista, sino que «estaba ya prefigurada en la dinámica y la lógica del desarrollo de la sociedad capitalista» (Wellmer, 1988: 66). El comunismo, tal es la formulación canónica empleada por Marx y Engels en el texto de 1846 La ideología alemana, era así «el movimiento real que acaba por superar el estado actual de cosas» (Marx y Engels, 1974).

Aunque Marx abandonaba efectivamente la jerga de la filosofía política y la crítica jovenhegeliana de la religión en favor de estudios económicos basados en la economía política de Adam Smith y David Ricardo, lo cierto es que introducía en su pensamiento nuevos términos que, como la idea de "alienación” y "reapropiación” de la esencia humana (Marx, 1984), eran herencia de Feuerbach -y, naturalmente, también del Hegel de la Fenomenología-. En este momento la tesis de la emancipación del proletariado adquiría la forma concreta de una reapropiación de su esencia enajenada -el producto del trabajo- mediante la abolición de la propiedad privada de los medios productivos. Marx localizaba así la contradicción real de la sociedad burguesa en la oposición entre capital y fuerza de trabajo. La toma de conciencia de la dramática consecuencia de este antagonismo, es decir, de la existencia empobrecida de una clase tan mayoritaria como específica de la sociedad burguesa, había de ser el paso primero para la anhelada fusión entre teoría y praxis: «con la acción revolucionaria del proletariado, Marx introduce de nuevo la praxis política en la misma teoría» (Habermas, 1987: 280).

Naturalmente, en este punto hemos dado ya con el primero y más elemental de los rasgos de la Teoría Crítica: la fusión entre los análisis teórico-empíricos y la praxis transformadora. Aunque esta conexión, y sobre todo la primacía de la praxis sobre la teoría, quedó formulada de forma insuperablemente clara en la famosa undécima tesis sobre Feuerbach, una sistematización de su significado profundo, es decir, de la conexión ya siempre operante entre "conocimiento" e "interés", no aparecería hasta el estudio programático de la Teoría Crítica elaborado por Max Horkheimer en 1937.

Como es sabido, Horkheimer establece una distinción entre "teoría tradicional" y "teoría crítica". Oponiéndose al presunto carácter desinteresado y puro de la ciencia, el autor se esfuerza por demostrar la existencia de una vinculación irrebasable, por así decir transcendental, entre toda forma de teoría y el mundo social del que en definitiva surge; es decir, la existencia de un vínculo con todos aquellos procesos a través de los cuales la especie en su conjunto se apropia de la naturaleza para organizar libremente su mundo social. Frente a la ceguera de la ciencia con respecto a su contexto de surgimiento, es decir, frente a su errónea autocomprensión en términos de "teoría pura", Horkheimer reivindica una noción de teoría comprendida «en su ligazón con procesos sociales».

La función ideológica de la teoría así considerada aparece ante la conciencia tan pronto como se observa que los intereses inconfesados de la ciencia están sujetos al propio aparato productivo. Horkheimer expresa hiperbólicamente esta tesis con una afirmación hoy

2 Con esta afirmación no pretendo sumarme a las filas de aquellos que, con Althusser, ven una ruptura radical entre el llamado "joven Marx" y el "Marx maduro". Una interesante interpretación actual del "Marx maduro", es decir, del Marx como crítico de la economía política, se encuentra en Ramas, 2018. 
muy conocida: «la relación entre las hipótesis y los hechos, finalmente, no se cumple en la cabeza del científico, sino en la industria» (Horkheimer, 2008: 230). Traer a conciencia la abstracción de la teoría tradicional con respecto a lo que algunos años antes Herbert Marcuse había llamado «su situación hermenéutica de partida» (Marcuse, 2011; RomeroCuevas, 2010) apresa descriptivamente la función de la ciencia en el orden dado, al mismo tiempo que anticipa normativamente su auténtica función social. La Teoría Crítica, como autoconocimiento del hombre con respecto a la historicidad de la sociedad en que habita, es consciente del propio interés que la mueve, que no es otro que «el interés de instaurar un estado de cosas racional» (Horkheimer, 2008: 232). La Teoría Crítica encuentra entonces su función en la explicitación de los intereses en que está inserta la concepción moderna de la ciencia, y en este sentido no es sino la expresión autoconsciente de los procesos de emancipación inherentes al desarrollo de las fuerzas productivas ${ }^{3}$.

Ahora bien, esta forma de teoría, que como hemos visto reconoce el contexto social del que surge y asume conscientemente el interés que le guía, no quedaría correctamente fundamentada si no pudiera explicitar el ideal emancipatorio que inspira en cada caso sus respectivos diagnósticos sociales. Ya adquiera la forma de una crítica de la economía política (Marx,1970), de una teoría del fascismo (Marcuse, 1968), de una crítica de la razón instrumental (Adorno y Horkheimer, 2009), de una denuncia contra la colonización del mundo de la vida (Habermas, 2010a) o de una teoría de la lucha por el reconocimiento (Honneth, 2007), la teoría crítica de la sociedad formula un diagnóstico social cuya plausibilidad descansa en su correcta fundamentación normativa. Pues, en efecto, una filosofía social que trate de identificar aquellos «procesos de desarrollo de la sociedad que se pueden entender como [...] "patologías de lo social”» (Honneth, 2011: 76); una filosofía, por tanto, que analice las barreras sociales que impiden formas adecuadas de autorrealización humana, ha de poder decir algo sobre el aspecto que habría de tener una sociedad racional. Aunque no se comprometa con modelos concretos de "vida feliz", la Teoría Crítica debe definir al menos la estructura de una sociedad liberada de aquellos rasgos patológicos que conducen a vidas masivamente alienadas. Independientemente de si esta definición opera en los términos de una antropología normativa, como en el joven Marx; en los de una teoría de la mimesis como relación no instrumental con la naturaleza, como en Adorno y Horkheimer; en los de una anticipación de comunidades ideales de comunicación, como en el caso de Apel y Habermas; o en los de una reconstrucción normativa de la idea de libertad social, como ha hecho el último Honneth siguiendo a Hegel, la Teoría Crítica se compromete a ofrecer un fundamento normativo de su propio diagnóstico: «para poder hablar de una patología social, que según el modelo de la medicina ha de ser accesible a un diagnóstico, hace falta una idea de normalidad que se refiere a la vida social en su totalidad» (Honneth, 2011: 115).

3 Axel Honneth ha detectado una contradicción en esta tesis: no es posible aclarar cómo la Teoría Crítica puede formular una crítica contra la sociedad dada si tan sólo constituye la autoconsciencia de un proceso que en todo caso se desarrolla conforme a su propia lógica, es decir, conforme a la contradicción entre fuerzas productivas y relaciones de producción. El momento del trabajo, dice Honneth, «no incluye dentro de sí el momento reflexivo que sería necesario para poner en tela de juicio ese orden social en el grado que preserva el desarrollo de las fuerzas productivas» (Honneth, 2009: 36). Creo que la teoría de los intereses del conocimiento desarrollada por Habermas y Apel en términos de una Erkenntnisanthropologie corrige la unilateralidad del planteamiento original. Véase Habermas, 1989 y Apel, 1985. 
En la medida en que también otras formas de filosofía social y política anteriores a Marx, como las que encontramos en los Discursos sobre el origen de la desigualdad de Rousseau (Rousseau, 1987; Neuhouser, 2012) o en las protestas del pensamiento contrarrevolucionario (Burke, 1990), se sirven de ideales normativos a cuya luz diagnostican procesos de racionalización patológica, la conexión entre crítica social y normatividad no es propiedad exclusiva de la Teoría Crítica. No obstante, a nosotros no nos interesa tanto ofrecer una visión de conjunto de este problema, cuanto explicar qué tipo de fundamentos normativos están a la base del que acaso constituye el más impresionante modelo contemporáneo de Teoría Crítica: la teoría de la acción comunicativa de Jürgen Habermas.

\section{La Teoría Crítica como teoría de la acción comunicativa}

En su teoría de la acción comunicativa, Habermas rescata la lectura marxista-occidental de la teoría weberiana de la racionalización, como proceso en discordia consigo mismo, para desde sus insuficiencias normativas emprender un tránsito en la Teoría Crítica desde el paradigma del sujeto hasta el paradigma de la intersubjetividad (Cortina, 2008). Según su lectura, con su crítica de la razón instrumental -que bebía al mismo tiempo de Marx, de Weber y de Lukács-, Adorno y Horkheimer no fueron capaces de explicar el significado de la instrumentalización de las relaciones sociales desde el punto de vista de la «vida violentada y deformada», pues no disponían de un trasfondo normativo a cuya luz esta forma de vida pudiera ser diagnosticada como efectivamente deformada (Habermas, 2010a: 444). Aquello que Adorno y Horkheimer sólo pueden mencionar metafóricamente, la relación mimética con la naturaleza, ha de ser explicado a juicio de Habermas en los términos de una intersubjetividad no violentada y mediada lingüísticamente. Bajo este nuevo paradigma, que abandona la primacía de la racionalidad teleológica en favor de la racionalidad comunicativa, el proceso de racionalización moderna puede ser reconstruido en términos ciertamente diferentes de los empleados tanto por Weber como por Adorno y Horkheimer en su lectura marxista de Weber.

Sirviéndose para ello de las aportaciones de la teoría de sistemas de Parsons, Habermas relee la problemática de la reificación (Verdinglichung) no ya como una absolutización de la razón instrumental, sino como el proceso de colonización del mundo de la vida por parte de la razón funcionalista propia de los subsistemas económico y político. Pero para que este diagnóstico tenga sentido, Habermas tiene que desarrollar primero tanto la idea de "racionalización comunicativa" del mundo de la vida, como el significado de una teoría de la sociedad que se compone de los elementos "sistema" y "mundo de la vida".

Con respecto a lo primero, Habermas recurre a Mead y Durkheim para mostrar cómo, lo mismo en el ámbito ontogenético que en el filogenético, la evolución identitaria y sociocultural opera en términos de una progresiva "lingüistización (Versprachlichung) de lo sacro". Las funciones de socialización e integración social, cumplidas originariamente por las prácticas rituales, van pasando progresivamente, con los procesos de modernización, a la acción comunicativa, y la autoridad de lo santo «va quedando gradualmente sustituida por la autoridad del consenso en cada caso fundado». Es así como la racionalidad comunicativa, el tipo de racionalidad que opera entre dos agentes que tratan de ponerse de acuerdo para coordinar sus acciones, cumple la función de una racionalización de los mundos de la vida. 
Como veremos más adelante, en sus estudios sobre pragmática universal Habermas había diferenciado tres relaciones pragmáticas que un sujeto, al actuar comunicativamente, podía entablar con el mundo: podía relacionarse con un mundo objetivo elevando pretensiones de verdad, con un mundo social elevando pretensiones de corrección normativa y con un mundo subjetivo elevando pretensiones de veracidad expresiva. La acción comunicativa consistía en este sentido en un proceso cooperativo de interpretación en el que al menos dos sujetos se ponen de acuerdo sobre una situación devenida problemática. En este contexto, el mundo de la vida queda definido como el marco común sobre el que se tematizan y problematizan pretensiones de validez y se procede a nuevas interpretaciones de la situación. Cuando un fragmento de ese "depósito de autoevidencias" que constituye el mundo de la vida queda tematizado por uno de los participantes, su ingenua solidez queda convertida en un hecho, una norma o una vivencia cuya validez, que ha sido puesta temporalmente entre paréntesis, sólo puede serle devuelta mediante la obtención de un nuevo acuerdo.

Ahora bien, y con esto damos con el segundo elemento mencionado, en el modelo de Habermas el mundo de la vida constituye solamente una de las esferas de la sociedad. Frente al idealismo hermenéutico de la sociología comprensiva, que aborda la sociedad y sus contradicciones únicamente desde la perspectiva del participante en el mundo de la vida, Habermas hace valer aquí los réditos teóricos de un enfoque que opera desde la perspectiva del observador de un sistema. Entendiendo la sociedad a la vez como sistema y como mundo de la vida, Habermas puede distinguir entre los procesos de reproducción simbólica, realizados mediante la acción comunicativa, y los procesos de reproducción material, que se atienen a imperativos funcionales de supervivencia basados en la acción teleológica. La diferencia entre ambos procesos es ahora muy evidente. El dinero y el poder aparecen como aquellos "medios de regulación" (Steuerungsmedien) sistémica que, ante la aparición de conflictos, no apelan a un desempeño discursivo de pretensiones de validez, sino que «desconectan la coordinación de la acción de la formación lingüística de consensos».

En la teoría de la evolución social que Habermas dibuja sobre la base de los conceptos "mundo de la vida" y "sistema" se dejan ver ya, naturalmente, las conexiones con esa dialéctica de la Ilustración que la Escuela de Frankfurt había apresado conjugando las categorías de Marx y Max Weber. En ella se aprecian por fin, en suma, los contornos de una nueva teoría crítica de la sociedad. Esa «incontenible ironía del proceso histórico universal de Ilustración» que Adorno y Horkheimer trataban de explicar con su tesis sobre el paralelismo entre el sometimiento de la naturaleza exterior y el sometimiento de la naturaleza interior, y cuyo origen primero se encuentra en la tesis marxiana de una socavación de los mundos de la vida tradicionales por parte del capital, queda aquí apresada en la siguiente fórmula: «los mecanismos sistémicos acaban desplazando las formas de integración social, incluso en aquellos ámbitos en los que la coordinación de la acción en términos de consenso no tiene sustituto posible alguno; es decir, incluso allí donde lo que está en juego es la reproducción simbólica del mundo de la vida. Entonces la mediatización del mundo de la vida adopta la forma de una colonización del mundo de la vida» (Habermas, 2010a: 690).

A diferencia de lo que ocurría en la versión marxiana de esta tesis, en el modelo de Habermas los efectos patológicos derivados de la colonización, tales como la monetarización y juridificación de relaciones sociales, no se hacen notar tan sólo en una clase específica -el proletariado-, sino que afectan a la sociedad moderna en su conjunto. Naturalmente que con 
este gesto Habermas se acerca más a sus predecesores en la Escuela de Frankfurt, que habían emprendido la Teoría Crítica en términos de crítica de la razón instrumental, que a posturas más claramente marxistas como la del joven Lukács. La teoría social de Adorno, Horkheimer y Marcuse, esa pesimista visión del mundo totalmente administrado, tiene para Habermas la ventaja de «advertir los síntomas de una deformación sistemáticamente inducida de los ámbitos de la vida estructurados comunicativamente» (Habermas, 2010a: 855). El error de este modelo, no obstante, consistió en haber reducido la racionalidad (Vernunft) a la racionalidad instrumental de los subsistemas autorregulados, pues semejante reducción privó a la crítica de la razón instrumental de todo criterio normativo racional desde el cual dar razón de sí misma.

Frente a esta incapacidad, por así decir estructural, de Adorno y Horkheimer para fundamentar teóricamente su propio diagnóstico, Habermas puede apelar a una forma diferente de racionalidad todavía no sepultada, que actúa como el trasfondo normativo sobre el cual se hacen evidentes las patologías sociales. Las estructuras de la racionalidad, tal es la tesis, deben ser buscadas en la práctica comunicativa cotidiana del mundo de la vida: «la teoría de la acción comunicativa puede asegurarse del contenido racional de estructuras antropológicas profundas en un análisis que inicialmente es sólo reconstructivo», es decir, que trata de hacer conscientes las estructuras de la acción y el entendimiento, y sobre ellas las formas distorsionadas de entendimiento. La Teoría Crítica, como teoría de la acción comunicativa, aspira por tanto a ese momento de incondicionalidad desde el cual fundamentar la propia crítica, a ese momento que, «con las pretensiones de validez susceptibles de crítica, viene inscrito en las condiciones mismas de los procesos de formación de un consenso». Solamente apoyados en la reconstrucción de estas estructuras de la racionalidad, estructuras que aparecen ya, como decía Habermas en su discurso inaugural de 1965 en Frankfurt, «con la primera frase que pronunciamos» (Habermas, 2010b), puede emitirse un diagnóstico crítico que, desde los inicios mismos de la Teoría Crítica, ha de tener la forma de una denuncia contra formas patológicamente reducidas de racionalidad. El descubrimiento de las estructuras lingüísticas del mundo de la vida constituye el requisito, por así decirlo, para la formulación de la crítica. Precisamente porque la crítica va dirigida contra la socavación de estas estructuras por parte de unos subsistemas económico y político fuera de control.

Voy a defender que, en la medida en que la pragmática transcendental ideada por Apel y Habermas trata de reconstruir las estructuras formales de la racionalidad comunicativa, ella constituye el auténtico fundamento normativo de esta Teoría Crítica. Para que esta tesis tenga sentido, no obstante, es necesario analizar primero el significado preciso de dicha teoría.

\section{La pragmática transcendental}

Aunque un análisis comparativo de los modelos de Apel y Habermas nos obligaría a diferenciar entre "pragmática transcendental” y "pragmática universal”, en la medida en que el ímpetu totalmente posmetafísico de Habermas le ha impedido siempre reconocer en su proyecto una "fundamentación filosófica última", en aras de la claridad expositiva utilizaré la expresión de Apel para referirme al proyecto conjunto ${ }^{4}$.

4 Además de por razones de claridad expositiva, creo que los argumentos ofrecidos por Habermas para "destranscendentalizar" su modelo no resultan del todo convincentes. Una formulación relativamente reciente 
En oposición a ciertos enfoques analíticos que hacen del lenguaje uno más de entre los muchos objetos de la ciencia empírica, Apel parte de un concepto "hermenéuticotranscendental del lenguaje" (Apel, 1985a) según el cual éste constituye al mismo tiempo el vehículo mediante el cual accedemos hermenéuticamente al mundo objetivo y social por medio de la interacción interpretativa con el resto de sujetos, y el objeto de un tipo de reflexión determinada, que trata de averiguar las condiciones de posibilidad y validez de ese acceso al mundo 5 . El lenguaje, por así decirlo, es al mismo tiempo "el tema y el medio" de la reflexión transcendental (Apel, 1985c). Ahora bien, en tanto es también medio de la ciencia, como tema se presenta bajo una determinación específica, que exige a quien lo estudia abandonar el método de la objetivación. Dado que el objeto de conocimiento que llamamos "argumentación lingüística" actúa como condición de posibilidad y validez de todo conocimiento -teórico y práctico-; dado, por decirlo en los términos del segundo Wittgenstein, que constituye una especie de "juego de lenguaje" de todos los demás juegos de lenguaje, una "metainstitución" de todas las instituciones, su estudio ha de realizarse en términos de autorreflexión transcendental.

El lenguaje no es sólo la «instancia mediadora en la relación sujeto-objeto de la teoría transcendental del conocimiento», sino que es él mismo el "punto supremo" de toda teoría del conocimiento. Permaneciendo fiel al marco transcendental kantiano, pero en el espíritu de Peirce y de la crítica del sentido de Wittgenstein, Apel logra ir más allá de un enfoque transcendental que, como dice Jesús Conill, en su origen «versaba sobre las condiciones de posibilidad de la constitución objetiva prelingüística» (Conill, 1992: 4). Apel hace reposar el punto irrebasable de la teoría del conocimiento en la «síntesis transcendental de la interpretación mediada lingüísticamente, como unidad del acuerdo sobre algo en una comunidad de comunicación». Ahora bien, si es que hemos de convenir en la posibilidad de una validez no meramente fáctica o contextual, sino universal, entonces debemos reconocer que los juegos lingüísticos individuales «llevan implícita la posibilidad de autotranscenderse por medio de la autorreflexión» (Apel, 1985c: 307). Si esto es así, entonces el propio hecho de la argumentación ya presupone, para que tenga sentido, el cumplimiento de ciertas condiciones universales que actúan como sus presupuestos pragmático-transcendentales. Como digno renovador del kantismo, el modelo de Apel entraña ya siempre un afán de universalización que se expresa en los propios procedimientos de justificación. Semejante renovación, no obstante, posee desde el principio un carácter hermenéutico, tal y como han visto algunos autores de la Escuela de Valencia. Aunque sólo en los procedimientos queda encarnado el núcleo universalista de una razón que al cabo puede trascender toda forma concreta de vida, dichos procedimientos se leen ya siempre en la praxis concreta de una sociedad, de suerte que su reconstrucción exige una "hermenéutica crítica desde la facticidad" (Conill, 2006).

Como no es difícil de ver, la filosofía del lenguaje reemplaza en este sentido a la teoría del conocimiento en tanto «reflexión sobre las condiciones lingüísticas de posibilidad del conoci-

de estos argumentos se encuentra en Habermas, 2006. Para una crítica a esta tentativa véase García-Marzá, 1992. Para una exposición exhaustiva del problema de la "fundamentación transcendental última" véase Cortina, 1986, Parte II.

5 Tal y como ha mostrado Juan Carlos Siurana, este concepto de "reflexión" juega un papel intrateóricamente ambivalente en el pensamiento de Apel. Véase Siurana, 1999. 
miento» (Apel, 1985c: 297). La posibilidad y validez del conocimiento depende entonces del principio regulativo de una formación crítica de consensos en lo que Apel llama aquí "comunidad ideal de comunicación". En la medida en que las acciones del entendimiento privado son sustituidas por las acciones del acuerdo público entre sujetos que practican actos de habla, la teoría del conocimiento reposa en una pragmática del lenguaje. En tanto esta pragmática trata de averiguar los elementos ya siempre presupuestos en el propio acto de argumentar, es además una pragmática transcendental. En el intento por reconstruir aquellos presupuestos pragmáticos de la argumentación que resultan normativamente relevantes, Apel ha encontrado la vía adecuada para ofrecer al mismo tiempo una "fundamentación filosófica última" del conocimiento válido y una fundamentación racional de la ética, entendida bajo el modelo de una ética de la corresponsabilidad solidaria de las acciones colectivas comprometida con un “cosmopolitismo para la convivencia internacional” (Martínez, 2003).

Con respecto a lo primero, Apel ha emprendido una interesante metacrítica del "racionalismo crítico" defendido por Popper y Albert (Apel, 1976). En semejante lectura, el autor no trata de poner en duda el principio del examen crítico ilimitado defendido por los racionalistas, sino mostrar que este principio presupone ya como su condición de posibilidad un principio de fundamentación filosófica última. El propio juego lingüístico del dudar, en el que sin duda se basa el principio del racionalismo crítico, presupone un momento de certeza indubitable. O, dicho de otra forma, la crítica tiene que presuponer un marco pragmáticotranscendental, unas condiciones de posibilidad no criticables, si es que no quiere incurrir ella misma en la autocontradicción de negar justamente lo que presupone en el acto mismo de negar. Así pues, no es por la vía de la deducción lógica, sino de la reflexión, que Apel logra mostrar la existencia de un juego transcendental del lenguaje como "institución de la crítica", es decir, como presupuesto de toda crítica que no puede ser negado más que incurriendo en una contradicción performativa. Falta por ver en qué sentido el propio acceso al juego lingüístico de la crítica no presupone ya otras condiciones transcendentales de posibilidad que, por su propia naturaleza, se sustraen al estudio formalista de Apel. Adela Cortina ha mostrado convincentemente cómo la propia competencia comunicativa exige que los interlocutores se reconozcan mutuamente en un sentido más amplio, a saber, a la vez como hablantes competentes y como sujetos constitutivamente vulnerables. Este reconocimiento sólo puede darse si, además de la argumentación formal, presuponemos en los seres humanos la capacidad de sentir emociones, de estimar valores y de formarse un juicio justo a través de la adquisición de ciertas virtudes (Cortina, 2007) ${ }^{6}$.

Con respecto a lo segundo, Apel muestra cómo al descubrimiento de los presupuestos pragmático-transcendentales operantes en toda forma de argumentación corresponde el descubrimiento de ciertas normas morales cuya validez incondicional es condición de posibilidad del sentido de la argumentación. Si, tal y como había mostrado Peirce, la validez del conocimiento depende por principio de la justificación de los enunciados lingüísticos

6 Aunque esta forma de reconocimiento amplio ha servido a Cortina para dar cuenta del problema de las fuentes de la obligación moral, es decir, del problema de la motivación en la ética, en una reciente discusión he podido comprobar que, en la medida en que todos los elementos introducidos por ella -vulnerabilidad, compasión, estimación de valores, etc.- cumplen un papel transcendental para el funcionamiento del propio modelo, forman parte también -aunque creo que en un nivel diferente al de la argumentación- del problema de la fundamentación normativa. 
en la comunidad actual de argumentación, ha de presuponerse que en esa comunidad real todos los miembros se reconocen como interlocutores válidos con los mismos derechos, es decir, como agentes de lo que Cortina ha llamado una "ética mínima" (Cortina, 1986). Ello significa, en pocas palabras, que «la objetividad de las mismas ciencias no valorativas ya presupone la validez intersubjetiva de normas morales» (Apel, 1985d: 376).

Las dos tesis anteriores constituyen, como puede verse, el germen teórico de lo que sólo unos años más tarde, con el impulso de Habermas, adquiriría la forma de una teoría consensual de la verdad (Habermas, 1994a) y una ética del discurso (Habermas, 2008). No obstante, la pragmática transcendental que está a la base de estos programas, y que Apel saca a la luz mediante su impresionante combinación de la hermenéutica filosófica, la crítica de las ideologías y la filosofía del lenguaje del último Wittgenstein, ha de permanecer hasta cierto punto oscura mientras no se diferencien con nitidez las partes proposicional y performativa de los actos de habla implicados en la argumentación. Es decir, hasta que no se expliqué qué significa el poder vinculante de la argumentación. A mi juicio, ha sido Habermas quien mejor ha desarrollado este aspecto fundamental del modelo.

Para analizar los sistemas de reglas a través de los cuales se generan situaciones de entendimiento y coordinación de la acción, Habermas diferencia cuatro tipos de actos de habla: los actos de habla comunicativos, que «sirven para expresar en general distintos aspectos del sentido del habla»; los constatativos, que «sirven para expresar el sentido del empleo cognitivo de oraciones»; los representativos o expresivos, que «sirven para expresar el sentido pragmático de la autopresentación que un hablante hace ante un público»; y los regulativos, que «sirven para expresar el sentido normativo de las relaciones interpersonales que establecen». Por otra parte, Habermas descubre una doble estructura cognitivo-comunicativa en todo acto de habla. Una situación de entendimiento posible exige que al menos dos agentes establezcan una comunicación simultáneamente en dos planos: «en el plano de la intersubjetividad, en que los sujetos hablan entre sí, y en el plano de los objetos (o estados de cosas) sobre los que se entienden» (Habermas, 1994b: 83-92).

Sobre la base de estas reflexiones, Habermas puede diferenciar en un segundo paso argumentativo cuatro pretensiones de validez contenidas en todo acto de habla: la inteligibilidad (Verständlichkeit), o pretensión de que la expresión simbólica empleada pueda ser comprendida por el hablante; la verdad (Wahrheit), o pretensión de que las afirmaciones empleadas prediquen algo que efectivamente posee el objeto sobre el que lo predican; la veracidad (Wahrhaftigkeit), o pretensión de que las manifestaciones expresivas formulen las auténticas intenciones del hablante; y la rectitud (Richtigkeit), o pretensión de que las normas vigentes que subyacen a manifestaciones normativas como mandatos o consejos puedan justificarse. La condición para la verdad de un enunciado o la corrección de una norma problematizados, es decir, de enunciados o normas que han dejado de pertenecer a ese trasfondo incuestionado que constituye la acción comunicativa del mundo de la vida, reside en que su pretensión de verdad o de corrección normativa pueda ser desempeñada en un discurso racional. En el ámbito del discurso, sólo los argumentos poseen fuerza necesaria para motivar el reconocimiento de una determinada pretensión de validez, es decir, sólo ellos pueden garantizar la obtención de un consenso. El problema evidente al que tiene que enfrentarse esta explicación es el de ofrecer un criterio para diferenciar entre un consenso sólo fácticamente alcanzado y un consenso fundado racionalmente, y 
para resolver semejante desafío Habermas introduce la conocida noción de "situación ideal de habla" como anticipo necesario de todo aquel que quiera participar en serio en una argumentación?

Habermas sigue sin duda a Apel en la tarea de reconstruir los presupuestos universales que se dan en todo acto de habla, es decir, aquello que «necesariamente hemos de presuponer ya siempre» como condiciones transcendentales de posibilidad del entendimiento. Con la ejecución de un acto de habla el hablante se ve sometido a la doble "coerción transcendental" de entablar pretensiones de validez y de presuponer que estas pretensiones pueden ser desempeñadas discursivamente. Ya sea mediante la utilización de argumentos, mediante interpretaciones hermenéuticas o mediante una actuación consecuente con las intenciones declaradas, el ejecutor de un acto de habla puede mostrar que existen buenas razones para reconocer lo que él dice (Habermas, 1994c). Como ya sabemos, el acto de habla posee al mismo tiempo una parte ilocucionaria, con la que el hablante entabla una relación intersubjetiva con el oyente, y una parte proposicional, que refiere a las experiencias y estados de cosas sobre los que hablante y oyente tratan de entenderse. Con la expresión "status realizativo", Habermas quiere significar que todo acto de habla contiene una "fuerza ilocucionaria", de suerte tal que con la emisión lingüística el agente realiza al mismo tiempo una determinada acción. El status realizativo sólo puede ser aprendido en la medida en que, entablando una relación interpersonal, el oyente admite o rechaza las pretensiones de validez asociadas a los actos de habla del hablante.

Aunque estas pretensiones de validez hacen presencia en el mundo de la vida primeramente sólo de forma ingenua e incuestionada, tras una eventual problematización aparecen como tema de desempeño discursivo; es decir, como el objeto de debate en un discurso teórico o práctico. Mientras que en los actos de habla constatativos aparece de forma preeminente la pretensión de validez que llamamos "verdad", por lo que su desempeño argumentativo exige transitar al discurso teórico; en los actos de habla regulativos el hablante implica una pretensión de corrección normativa, cuya aceptación por parte del oyente significa o bien el reconocimiento de que dicho acto de habla se apoya en normas vigentes, o bien, en el nivel superior que representa el discurso práctico, que dichas normas vigentes son de hecho normas válidas ${ }^{8}$. Independientemente de cuál sea la pretensión tematizada, el "logro" del acto de habla tiene como resultado el restablecimiento de una relación interpersonal que se había vuelto problemática, pues con dicho logro el hablante hace una oferta que el oyente puede aceptar o rechazar. Los discursos son en este sentido, como dice García-Marzá, «la segunda oportunidad que nos brinda el lenguaje para construir una interacción» (García-Marzá, 1992: 50).

Como vimos más arriba, el reto de Habermas consiste en explicar en qué consiste exactamente este compromiso del hablante, es decir, qué significa la fuerza ilocucionaria vinculante por la que un oyente puede confiar en las obligaciones contraídas por el hablante en su acto de habla. Esta fuerza vinculante se explica por la posibilidad, inherente al habla misma, de transcender en todo momento la aceptación ingenua de pretensiones de validez

7 Ha sido Albrecht Wellmer quien ha formulado la crítica más incisiva al papel que juega esta idea en la teoría consensual de la verdad, y posteriormente también en la ética del discurso. Véase Wellmer, 1994.

8 La inteligibilidad que caracteriza a los actos de habla comunicativos no puede en rigor tematizarse, sino que ha de presuponerse ya siempre bajo riesgo de que la propia comunicación quede interrumpida. Por su parte, en los actos de habla expresivos o representativos el hablante implica una pretensión de veracidad cuya aceptación sólo puede motivarse mediante un comportamiento consecuente con lo exteriorizado. 
que caracteriza a la acción comunicativa y elevarse reflexivamente a ese nivel en el que únicamente cuentan las buenas razones, y en el que todas las pretensiones de validez pueden ser tematizadas hasta la restauración del consenso. Naturalmente, el consenso así obtenido ha de poder ser considerado válido, para lo cual Habermas debe definir aquellas condiciones formales bajo las cuales la obtención de consensos garantiza inmediatamente su carácter racional: «un consenso alcanzado argumentativamente es condición suficiente de resolución o desempeño de pretensiones de validez discursivas si y sólo si en virtud de las propiedades formales del discurso está asegurado el paso libre entre los distintos niveles del discurso. Y, ¿cuáles son las condiciones formales que cumplen esa condición? Mi tesis es: las propiedades de una situación ideal de habla» (Habermas, 1994a: 153). Semejante situación no es ni un fenómeno empíricamente existente, ni una mera construcción que haya de actuar como ideal regulativo. Es, por el contrario, una «suposición inevitable que recíprocamente nos hacemos en los discursos». Aun poseyendo un carácter contrafáctico, en tanto suposición inevitable está ya operando efectivamente en el proceso de comunicación.

\section{La pragmática transcendental como fundamento normativo de la Teoría Crítica}

En el punto anterior habíamos visto que el nexo entre pragmática transcendental y teoría crítica de la sociedad había de ser buscado en el concepto "mundo de la vida", precisamente en tanto las estructuras linguiísticas y las formas de acción configuradas en su seno, ambas susceptibles de una reconstrucción pragmático-transcendental, resultaban ser las víctimas del proceso de colonización. El medio de coordinación de las acciones que Habermas llamaba "entendimiento" era sustituido en este proceso por medios de regulación sistémica como el dinero y el poder. Para apresar el sentido profundo de esta tesis, no obstante, hemos tenido que analizar cómo es posible que los sujetos puedan coordinar sus acciones y reproducir sus saberes culturales en base a consensos. En la medida en que Apel brinda, con su análisis pragmático-transcendental del lenguaje, una explicación de las condiciones de posibilidad del conocimiento válido, su modelo ofrece la explicación adecuada de esas estructuras comunicativas del mundo de la vida, por mucho que su propia autocomprensión -en un espíritu totalmente kantiano- no apunte (tanto) a una fundamentación normativa de la Teoría Crítica-como sí hace la de Habermas-, cuanto a una fundamentación filosófica del conocimiento teórico y práctico.

Ahora podemos ver de forma muy clara la relación entre la pragmática transcendental de Apel y la Teoría Crítica en su versión habermasiana. Al exponer las condiciones de posibilidad del conocimiento válido, unas condiciones que resultan normativamente relevantes por cuanto se correlacionan con los principios de una ética mínima, Apel está definiendo exactamente la forma no patológica de reproducción del saber cultural y coordinación de las acciones entre los agentes. Justamente el tipo de organización que, como consecuencia de procesos vinculados con la burocratización y la monetarización del mundo de la vida, queda distorsionada en su propia estructura comunicativa. Con el triunfo de estos procesos patológicos, ni siquiera el argumento de la contradicción performativa puede rescatar los presupuestos pragmático-transcendentales de la argumentación, sencillamente porque la argumentación, el tipo de coordinación de las acciones que depende de las respuestas "estoy de acuerdo" y "no estoy de acuerdo", queda eliminada como forma de coordinación válida. 
Ahora bien, aunque sin duda por esta vía indirecta de la fundamentación normativa la pragmática transcendental apeliana queda conectada con la teoría crítica habermasiana, existe a mi juicio una segunda vía, desde luego más inmediata, de mostrar la pertenencia de Apel a la corriente de pensamiento que, en general, llamamos "Teoría Crítica". Esta conexión se observa de forma extraordinariamente clara cuando reparamos no tanto en la fundamentación normativa, cuanto en la forma concreta del diagnóstico social ofrecido por Apel.

Hemos visto que la idea de una comunidad ideal de comunicación es anticipada, según la explicación de Apel, por cada miembro de la comunidad real de comunicación. Esta anticipación sirve a Apel, entre otras cosas, como "reserva" crítico-ideológica contra la propia comunidad real de comunicación, que la hermenéutica había presupuesto sin más como exenta de coacciones. En esta "contradicción dialéctica fundamental" entre las comunidades real e ideal de comunicación, y especialmente en el interés, definido una y otra vez por Apel como un postulado moral, por eliminar esta contradicción, encontramos sin duda una nueva formulación del interés emancipatorio de la Teoría Crítica. En la medida en que Apel ha reconocido el valor normativo del acuerdo idealizado, se observa con claridad que el principal obstáculo para lograr una sociedad emancipada radica en la «contradicción entre la comunidad ideal y la real de comunicación». Sólo en este momento Apel puede, a mi juicio legítimamente, abandonar el rol del hermeneuta que se guía por el interés en el acuerdo para adoptar el controvertido rol del crítico ideológico. Sólo situado en este rol, en el rol de un observador capaz de apresar la dimensión histórica y material de la sociedad, y por ello mismo de advertir que «los hombres no han hecho hasta ahora su historia» de forma totalmente transparente (Apel, 1985f: 115), Apel puede enfrentar aquellas formas de vida y juegos lingüísticos «cosificados como cuasi-naturaleza, que hasta ahora dificultaban un acuerdo completo». La figura teórica de la crítica ideológica ha de provocar entonces «la autocomprensión reflexiva de los hombres para romper emancipatoriamente sus barreras», es decir, ha de actuar como la suspensión, sólo provisional, de la comunicación hermenéutica en favor de una explicación objetivante. Si es que Apel quiere evitar reivindicar para sí los capciosos privilegios epistémicos de la vanguardia revolucionaria, semejante suspensión, no obstante, ha de estar destinada a hacerse superflua a sí misma, es decir, debe transformarse en una autocomprensión reforzada y libre de barreras de los propios sujetos alienados (Kettner, 1994).

Que la emancipación significa entonces la realización histórica de la comunidad ideal en la comunidad real, eso es ahora algo muy evidente. Y no es menos evidente que esta realización histórica del ideal ya siempre anticipado se corresponde con la meta emancipatoria, contenida también en la teoría de la acción comunicativa de Habermas, de eliminar «todas las asimetrías, producidas socialmente, del diálogo interpersonal».

\section{Conclusiones}

Un breve repaso por algunos de los elementos estructurales de la Teoría Crítica nos ha conducido al problema, totalmente decisivo desde un punto de vista filosófico, de las fuentes de normatividad de la crítica. Una vez analizados, en un segundo paso argumentativo, los contornos que adopta la Teoría Crítica en su versión habermasiana, es decir, el diagnóstico de una colonización del mundo de la vida por parte de imperativos del sistema, hemos podido dedicarnos a reconstruir la teoría de la competencia comunicativa o pragmática 
transcendental. A la luz de los tres pasos anteriores se hizo evidente, en cuarto lugar, que esta última teoría constituía la genuina fundamentación normativa de la Teoría Crítica como teoría de la acción comunicativa, pues con ella quedaban reconstruidos los presupuestos transcendentales de formas no patológicas de entendimiento lingüístico.

Con esta conexión entre pragmática transcendental y diagnóstico social quedaba justificada la contribución de Apel al paradigma teórico de la Teoría Crítica. Pero este rodeo por el problema de la normatividad solamente servía para confirmar una intuición que, en el fondo, estaba ya prejuzgada mucho antes. Tan pronto como Apel postula la necesidad de superar históricamente la contradicción entre la comunidad ideal de comunicación y la comunidad real, sobre la que aquélla opera ya siempre inmanentemente, su filosofía se compromete con un particular interés transformador. ¿Qué es esta asunción consciente del interés por clausurar la distancia entre idealidad y facticidad sino un nuevo intento, ambiciosamente justificado en términos de hermenéutica transcendental, de ofrecer una teoría crítica de la sociedad?

\section{Bibliografía}

ADORNO, T. W. y Horkheimer, M. (2009). Dialéctica de la Ilustración, Madrid, Trotta.

APEL, K. O. (1976). "Das Problem der philosophischen Letztbegründung im Lichte einer transzendentalen Sprachpragmatik", en: B. Kanitscheider (ed.): Sprache und Erkenntnis, Innsbruck, pp. 55-82.

APEL, K. O. (1985a). "El concepto hermenéutico trascendental del lenguaje”, en: La transformación de la filosofía, Madrid: Taurus, vol. II, pp. 315-340.

APEL, K. O. (1985b). "De Kant a Peirce: la transformación semiótica de la lógica transcendental", en: La transformación de la filosofía, Madrid: Taurus, vol. II, pp. 149-168.

APEL, K. O. (1985c). "El lenguaje como tema y medio de la reflexión trascendental", en: La transformación de la filosofía, Madrid: Taurus, vol. II, pp. 297-314.

APEL, K. O. (1985d). "El a priori de la comunidad de comunicación y los fundamentos de la ética”, en: La transformación de la filosofía, Madrid: Taurus, vol. II., pp. 341-414.

APEL, K. O. (1985f). "Cientística, hermenéutica y crítica de las ideologías”, en: La transformación de la filosofía, Madrid: Taurus, vol. II, pp. 91-120.

BURKE, E. (1990). Reflexiones sobre la Revolución francesa, Madrid: Rialp.

CONILL, J. (2006). Ética hermenéutica. Crítica desde la facticidad, Madrid: Tecnos.

CONILL, J. (1992). "Apel y Wittgenstein sobre la crítica del sentido: ¿de la lógica a la antropología?", Pensamiento, n 189 (48), pp. 3-31.

CORTINA, A. (1986). Ética mínima, Madrid: Tecnos.

CORTINA, A. (2007). Ética de la razón cordial, Oviedo: Nobel.

CORTINA, A. (2008). La Escuela de Fráncfort. Crítica y Utopía, Madrid: Síntesis.

GARCÍA-MARZÁ, D. (1992). Ética de la justicia, Madrid: Tecnos.

HABERMAS, (1987). "Entre ciencia y filosofía. El marxismo como crítica", en: Teoría y Praxis. Madrid: Tecnos, pp. 216-272.

HABERMAS, J. (1989). Conocimiento e interés, Madrid: Taurus.

HABERMAS, J. (1994a). "Teorías de la verdad", en: Teoría de la acción comunicativa. Complementos y estudios previos, Madrid: Cátedra, pp. 113-158. 
HABERMAS, J. (1994b). "Lecciones sobre una fundamentación de la sociología en términos de teoría del lenguaje", en: Teoría de la acción comunicativa. Complementos y estudios previos, Madrid: Cátedra, pp. 19-112.

HABERMAS, J. (1994c). “QQué significa pragmática universal?”, en: Teoría de la acción comunicativa. Complementos y estudios previos, Madrid: Cátedra, pp. 299-368.

HABERMAS, J. (2006). "Sobre la arquitectónica de la diferenciación de discursos", en: Entre naturalismo y religión. Barcelona: Paidós, pp. 83-104.

HABERMAS, J. (2008). "Ética del discurso. Notas para un programa sobre su fundamentación”, en: Conciencia moral y acción comunicativa, Barcelona: Trotta, pp. 53-119.

HABERMAS, J. (2010a). Teoría de la acción comunicativa, Madrid: Trotta.

HABERMAS, J. (2010b). "Conocimiento e interés", en: Ciencia y técnica como ideología, Madrid: Tecnos, pp. 159-181.

HONNETH, A. (2007). La lucha por el reconocimiento, Barcelona: Crítica.

HONNETH, A. (2009). Crítica del poder, Madrid: Antonio Machado.

HONNETH, A. (2011). "Patologías de lo social: tradición y actualidad de la filosofía social", en: La sociedad del desprecio, Madrid: Trotta, pp. 75-126.

HORKHEIMER, M. (2008). “Teoría tradicional y teoría crítica”, en: Teoría Crítica, Buenos Aires: Amorrortu, pp. 223-271.

KETTNER, M. (1994). "Ideologiekritik und Psychoanalyse. Zwei Seiten einer hermeneutischen Medaille?” En: K. O. Apel \& M. Kettner (Eds.). Mythos Wertfreiheit. Frankfurt/ New York: Campus Verlag, pp. 49-76.

KETTNER, M. (1996). "Karl-Otto Apel's contribution to critical theory", en: D. M. Rasmussen (ed.): Handbook of Critical Theory, London, pp. 258-286.

MARCUSE, H. (1968). "La lucha contra el liberalismo en la concepción totalitaria del Estado", en: Cultura y Sociedad, Buenos Aires: Sur, pp. 15-44.

MARTÍNEZ, E. (2003). "Ética cosmopolita para la convivencia internacional", Daimon, no 29 , pp. 171-182.

MARCUSE, H. (2011). "Para una confrontación con Sociología como ciencia de la realidad de Hans Freyer”, en: Entre hermenéutica y teoría crítica. Artículos 1929-1931, Barcelona: Herder, pp. 173-198.

MARX, K. (1970). Contribución a la crítica de la economía política, Madrid: Alberto Corazón Editor.

MARX, K. (1984). Manuscritos: Economía y Filosofía, Madrid: Alianza.

MARX, K. (2013). Introducción a la crítica de la filosofía del derecho de Hegel, Valencia: Pre-Textos.

MARX, K. y Bauer, B. (2009). La cuestión judía, Barcelona: Anthropos.

MARX, K. y Engels, F. (1974). La ideología alemana, Barcelona: Grijalbo.

NEUHOUSER, F. (2012). "Rousseau und die Idee einer 'pathologischen' Gesellschaft", Politische Vierteljahresschrift, n ${ }^{\circ} 53$ (4), pp. 628-645.

RAMAS, C. (2018). Fetiche y mistificación capitalistas. Madrid: Siglo XXI.

ROMERO-CUEVAS, J. M. (2010). "Herbert Marcuse y los orígenes de la teoría crítica. Una aproximación", en: H. Marcuse y los orígenes de la teoría crítica. México D. F.: Plaza y Valdés, pp. 7-76 
ROUSSEAU, J. J. (1987). Discurso sobre el origen y los fundamentos de la desigualdad entre los hombres, Madrid: Tecnos.

SIURANA, J. C. (1999). "La evolución del pensamiento de Karl-Otto Apel frente al problema de la reflexión", Anthropos, no 183, pp. 100-105.

WELLMER, A. (1988): "Razón, utopía y la dialéctica de la ilustración”, en: A. Giddens (Ed.), Habermas y la modernidad, Madrid: Cátedra.

WELLMER, A. (1994). Ética y diálogo, Barcelona: Anthropos. 